\title{
¿JÓVENES O ADULTOS? UN ESTUDIO DE LAS TRANSICIONES DESDE LA NIÑEZ EN SECTORES POBRES URBANOS
}

\author{
MARÍA EUGENIA RAUSKY*
}

\begin{abstract}
RESUMEN
En el presente artículo exploramos cómo se producen las transiciones desde la niñez en sectores pobres. Reconociendo que el estudio de las transiciones se ha concentrado en dos grupos etarios, - por un lado, el análisis del paso de la juventud hacia la adultez y por otro, el de la edad adulta hacia la ancianidad (Blanco, 2011) - , hemos encontrado en América Latina un vacío en los estudios sobre las transiciones que se presentan desde la infancia. Atentos a esta cuestión, en el presente trabajo exploramos qué características asumen las mismas en sectores pobres. Se analizan los cambios y continuidades en las trayectorias vitales (laborales, educativas y conyugales) de un grupo de ex-niños —entrevistados durante 2004 y 2008, y vueltos a entrevistar en 2013 - , que hoy son jóvenes y habitan en la ciudad de La Plata/Buenos Aires, buscando reconocer las particularidades que asumen las transiciones desde la niñez en sectores afectados por la pobreza estructural, la desigualdad y la precariedad laboral. ¿Bajo qué circunstancias se encuentran quienes vieron transcurrir su infancia en una situación doblemente desventajosa tanto por su condición de pobres y de trabajadores infantiles? ¿Qué eventos dan cuenta de las transiciones desde la niñez? ¿Cómo se experimenta dicha transición? ¿Qué particularidades presenta? ¿Se desarrolla un pasaje directo de la condición de niño a la de adulto? O bien, ¿se puede pensar a la juventud como un período más breve en la vida de las personas que viven en condiciones de pobreza? El trabajo adopta la perspectiva del curso de vida — que considera que las transiciones constituyen períodos especialmente vulnerables en la experiencia biográfica de los individuos - y se vale de una estrategia metodológica cualitativa basada en información diacrónica de carácter prospectivo.
\end{abstract}

PALABRAS CLAVE: CURSO DE VIDA, TRANSICIONES, NIÑEZ, JUVENTUD

* Argentina. Licenciada en Sociología, Universidad Nacional de la Plata. Magíster en Metodología de la Investigación, Universidad de Bologna/Tres de Febrero. Doctora en Cs. Sociales, Universidad de Buenos Aires. Se desempeña como investigadora del CIMECS-IDIHCS/UNLP-CONICET y como docente del Departamento de Sociología de la Facultad de Humanidades y Cs. de la Educación de la UNLP. E-Mail: eugeniarausky@gmail.com. Este trabajo se enmarca en el proyecto «Género y edad en estudios de caso sobre pobreza y políticas sociales en el Gran La Plata», dirigido por Susana Ortale y Amalia Eguía y subsidiado por el Programa de Incentivos a la Investigación del Ministerio de Educación de la Nación y el CONICET. 


\title{
JOVENS OU ADULTOS? UM ESTUDO DAS TRANSIÇÕES DA INFÂNCIA EM ÁREAS POBRES URBANAS
}

\begin{abstract}
RESUMO
No presente artigo estudamos como se produzem as transições da infância em áreas pobres. Reconhecendo que o estudo das transições se concentrou em dois grupos etários, por um lado, a análise da passagem da juventude para a fase adulta e por outro, aquele da fase adulta para a velhice (Blanco, 2011), encontramos na América Latina um vazio nos estudos sobre as transições que se apresentam da infância. Atentos a esta questão, no presente trabalho estudamos que características assumem em áreas pobres. Analisam-se as mudanças e continuidades nas trajetórias de vidas (laborais, educativas e conjugais) de um grupo de ex-crianças, entrevistadas durante 2004 e 2008, e entrevistadas novamente em 2013, que na atualidade são jovens e moram na cidade de La Plata/ Buenos Aires, procurando reconhecer as particularidades que assumem as transições da infância em áreas afetadas pela pobreza estrutural, a desigualdade e a precariedade laboral: Sob que circunstâncias estão aqueles que viram decorrer sua infância em uma situação duplamente desvantajosa — por sua condição de pobres e de trabalhadores infantis-? Que eventos mostram as transições da infância? Como são experimentadas estas transições? Que particularidades apresentam? É desenvolvida uma passagem direta da condição de criança para a de adulto? ou É possível pensar a juventude como um período mais breve na vida das pessoas que vivem em condições de pobreza? $\mathrm{O}$ trabalho adota a perspectiva do curso da vida — que considera que as transições constituem períodos especialmente vulneráveis na experiência biográfica dos indivíduos - e utiliza uma estratégia metodológica qualitativa baseada em informação diacrônica de caráter prospectivo.
\end{abstract}

\section{PALAVRAS CHAVE: CURSO DA VIDA, TRANSIÇÕES, INFÂNCIA, JUVENTUDE}

\section{YOUNG OR ADULTS? A STUDY OF TRANSITIONS FROM CHILDHOOD IN POOR URBAN AREAS}

\begin{abstract}
In this article we study how transitions occur from childhood in poor urban areas. Recognizing that the study of transitions has been focused on two age groups, on one hand, the analysis of the transition from youth to adulthood and on the other, from adulthood to old age (Blanco, 2001), we have found a gap in the studies of transitions from childhood in Latin American. Considering this, in this work we study what characteristics assume the same in poor areas. Also, changes and continuities in the vital trajectories (work, education and marriage) of a group of former children - interviewed during 2004 and 2008 and interviewed again in 2013 - are analyzed. Today, they are young and live in the city of La Plata/Buenos Aires. It aims to recognize the particularities assume transitions from childhood in areas affected by structural poverty, inequality and job insecurity: Under what circumstances are those who viewed spend their childhood in a doubly disadvantaged, because of their poor condition and child workers? What events show the transitions from childhood? How this transition is experienced? What particularities does it have? Is a direct passage from childhood to adulthood developed? or Is it possible to consider youth as a shorter period in life of those who live in poor conditions? This work takes the life course approach — which considers that transitions are especially vulnerable periods in the life experience of individuals - and uses a qualitative methodological strategy based on prospective diachronic information.
\end{abstract}

KEY WORDS: LIFE COURSE, TRANSITIONS, CHILDHOOD, YOUTH 


\section{INTRODUCCIÓN}

COMO LO HAN DESTACADO diversas investigaciones de la antropología, los sentidos y significados asociados a los grupos de edad han variado tanto histórica como culturalmente. En todos los tiempos y sociedades se han producido diferenciaciones de la población según las edades; distinciones que han marcado el modo en que se han organizado las etapas de la vida, hoy entendidas en sociedades occidentales como niñez, juventud, adultez y vejez. En este marco es que las fronteras que se trazan entre las expectativas asociadas a la edad suelen ir definidas por una serie de derechos, deberes, formas de actuar, etcétera, delimitadas por momentos de transición que difieren también según criterios relacionados con la pertenencia étnica, de clase y género.

De acuerdo con ello, en el presente trabajo buscamos explorar cómo se produce la transición de la niñez a la juventud en sectores pobres. Analizamos los cambios y continuidades en las trayectorias vitales (laborales, educativas y conyugales) de un grupo de ex-niños entrevistados entre los años 2004 y 2008; es decir, hace cinco y nueve años, vueltos a entrevistar en 2013, pertenecientes a sectores pobres de la ciudad de La Plata. Evaluamos aspectos relativos a eventos del mundo familiar, educativo, laboral, y residencial, considerando sus interrelaciones y confluencias, e incorporando al análisis cuestiones relativas a la estructura de oportunidades. ${ }^{1}$

Para el estudio de las transiciones utilizamos desde el punto de vista teórico-metodológico, la perspectiva del curso de vida, entendida como la secuencia de las distintas etapas de la vida reguladas socialmente según la edad, haciendo uso de relatos biográficos (Bertaux, 2005) tomados a partir de entrevistas en profundidad.

Cabe aclarar que aquí presentamos resultados parciales de una investigación en curso, de la que escogimos una serie de casos. Lo interesante es que cada uno de ellos refleja cierta heterogeneidad en los patrones de transición. Tomamos los relatos de cuatro jóvenes

1 Se reconoce que la noción de estructura de oportunidades fue desarrollada - entre otros - por Preworski. En América Latina los estudios de Katzman la han trabajado en extenso, definiéndola como «las probabilidades de acceso a bienes, a servicios o al desempeño de actividades. Estas oportunidades inciden sobre el bienestar de los hogares, ya sea porque permiten o facilitan a los miembros del hogar el uso de los propios recursos o porque les proveen recursos nuevos» (Katzman, 1999:9). 
- dos varones y dos mujeres - en dos momentos de su vida diferentes: durante la niñez y en la juventud. Paralelamente, también recuperamos los relatos de los padres. Se trata de un estudio diacrónico de carácter prospectivo.

En función de los objetivos propuestos, la estrategia expositiva que elegimos recupera:

- Un breve repaso por las características de la perspectiva del curso de vida, la justificación de su elección en este estudio y la importancia de analizar las transiciones.

- La explicación de las decisiones metodológicas seguidas en esta investigación.

- Una caracterización del contexto argentino.

- El análisis de las transiciones, plasmadas en experiencias biográficas, de los jóvenes entrevistados tomadas en su totalidad. ${ }^{2}$

\section{LA PERSPECTIVA DEL CURSO DE VIDA Y LA IMPORTANCIA DEL ANÁLISIS DE LAS TRANSICIONES}

El enfoque del curso de vida constituye una perspectiva desde la cual se puede estudiar el nexo entre las vidas individuales y el cambio social, más precisamente procura analizar cómo las fuerzas sociales moldean los cursos de vida individuales y colectivos y viceversa (Blanco y Pacheco, 2003).

Siguiendo los desarrollos teóricos de las ciencias sociales, este enfoque hereda la preocupación por desterrar ciertas oposiciones clásicas presentes en el campo —estamos pensando aquí en los pares conceptuales «subjetivo/objetivo», «sujeto/estructura», «individuo/sociedad»buscando desplazarlas y/o superarlas. ${ }^{3}$

$\mathrm{Si}$ bien se reconoce que los textos pioneros fueron escritos en los años sesenta, fue recién en la década del setenta cuando comenzó a desarrollarse plenamente este enfoque, destacándose los aportes de Elder en sociología y de Hareven en historia (Blanco, 2011).

Elder (1994) plantea que el paradigma del curso de vida refiere al entrelazamiento de «trayectorias» regladas por la edad, o sea, al movimiento a lo largo de la estructura de edad, que abarca una variedad

2 Vale aclarar que por razones de extensión lo hacemos de un modo acotado.

3 Los trabajos de Bourdieu (2007), Giddens (1998) y Corcuff (2013) —entre otros - son ejemplo de ello. 
de ámbitos relacionados entre sí - trabajo, escuela, etcétera-y las «transiciones» de corto plazo - las cuales van desde el abandono de la escuela hasta el retiro de la vida laboral-. Las «transiciones» definidas como cambios de estado, indican la asunción de nuevos roles y están incrustadas en las «trayectorias». A estos dos ejes organizadores del análisis del curso de vida, se agrega un tercero, el concepto de «turning point», el cual hace alusión a eventos no previsibles que provocan una discontinuidad en las trayectorias vitales y por ende, fuertes modificaciones en el curso de vida (Blanco 2011). ${ }^{4} \mathrm{Si}$ la asociación entre roles y edad es fundamental en el estudio del curso de vida, de esta aproximación se desprende lógicamente la centralidad que adquiere la consideración de la dimensión sociocultural de la edad. Como bien lo han mostrado distintos trabajos, la edad no se limita a un puro dato biológico o cronológico, sino que es también una construcción cultural, dotada de significados. Feixa (1996) subraya que si bien los individuos experimentan a lo largo de su vida un desarrollo fisiológico y mental determinado por su naturaleza, y que las distintas culturas compartimentan el curso de la biografía en períodos a los que asignan determinadas propiedades que categorizan a los individuos y pautan sus comportamientos de acuerdo a etapas, los mismos varían culturalmente. La no universalidad en los modos de dotar de sentido a las distintas etapas de la vida da cuenta del carácter histórico y culturalmente relativo de la división de edades y de la variabilidad que puede asumir de acuerdo a las clásicas diferencias de género y de clase. Queda claro que el curso de vida asume características distintas según la pertenecía cultural, de clase, de género, como así también al momento histórico en que los sujetos viven. ${ }^{5}$

4 Adicionalmente Elder (1994) define cuatro ejes fundamentales para dicho paradigma: a) la interrelación entre las vidas humanas y el tiempo histórico; b) el timing, entendido como el momento en que sucede un evento. Se supone que hay eventos o transiciones que acontecen temprana o tardíamente según las expectativas normativas y creencias asociadas a la edad, según el momento o edad de la vida en que ocurran, las consecuencias pueden ser muy distintas; c) la noción de vidas interconectadas, que posibilita analizar la interdependencia de la trayectoria de un individuo respecto de otros grupos o individuos; y d) la agencia humana, que destaca el papel activo del sujeto en la definición del curso de vida, sin desatender a los constreñimientos estructurales.

5 Al respecto de estos cambios se pueden consultar - entre otros - el trabajo de Deber (1997), quien repasa los cambios en el curso de vida 
Como ya mencionamos, el curso de vida puede definirse como un patrón de sucesivos eventos y roles asociados con la edad, expresados en normas y valores que establecen expectativas, derechos y obligaciones y que sirven para estructurar las experiencias biográficas. Asimismo también planteamos que las nociones de trayectoria, transiciones y turning point son las organizadoras del análisis que recupera esta perspectiva. La importancia que adquiere el estudio de las transiciones del curso de vida se relaciona con el interés por comprender el funcionamiento rutinizado y ordenado de la sociedad. Ellas dan cuenta de los sucesivos marcadores biográficos en el camino que los individuos transitan desde su nacimiento hasta su deceso. El enfoque del curso de vida entiende que las transiciones en cualquier dominio pueden tener consecuencias inmediatas en otros dominios o efectos acumulativos en la vida de los individuos, pueden redireccionar o reforzar las trayectorias de vida de los sujetos provocando tensiones o afectando importantes dimensiones de la vida cotidiana. Asimismo para evaluar las consecuencias que tienen en el largo plazo debe evaluarse la naturaleza, calendario y orden en que se dan las transiciones y cómo los sujetos se acomodan a ellas (Tuirán, 2001).

El estudio de las transiciones se ha concentrado en dos grupos etarios, por un lado, el análisis de la juventud hacia la adultez y por otro, el de la edad adulta hacia la ancianidad (Blanco, 2011). Confirmando esto, hemos encontrado en América Latina un vacío en los estudios sobre las transiciones que se producen desde la infancia. Atentos a esta cuestión, en este trabajo buscamos explorar cómo se desarrolla la transición desde la niñez en un grupo de sujetos pertenecientes a sectores pobres. Analizamos los cambios y continuidades relativos a eventos del mundo familiar, educativo, laboral, y aspectos relativos a su sociabilidad, observando sus interrelaciones y confluencias, e incorporando al análisis aspectos macroestructurales - recordemos que la perspectiva del curso de vida enfatiza la necesidad de comprender la interrelación entre biografías individuales y estructura de oportunidades- Si consideramos la secuencia de las transiciones de vida típicas de la sociedad occidental diríamos sin lugar a dudas que la etapa que sigue a la niñez es la juventud, en este sentido los sujetos entrevistados en la actualidad serían considerados jóvenes.

en las diferentes etapas de la sociedad occidental - premoderna, moderna y posmoderna - y el de Hareven (1999) basado en el análisis de la sociedad norteamericana. 
Las transiciones constituyen períodos especialmente vulnerables en la experiencia biográfica de los individuos, y esto es así tanto por las incertidumbres y expectativas que se depositan en ellas, como por el carácter condicionante que tienen sobre el futuro de las trayectorias a las que se asocian. Los riesgos a los que las personas se enfrentan a lo largo de su vida, son más importantes y determinantes para el futuro si se dan en un período de transición (Saraví, 2009). La idea se fundamenta en que en el curso de vida las experiencias actuales y futuras están condicionadas por experiencias y circunstancias previas. Esta perspectiva es particularmente útil en la medida en que el grupo de sujetos estudiados ha vivido y vive en condiciones de extrema vulnerabilidad. En este sentido cabe la siguiente pregunta: ¿qué particularidades asumen las transiciones desde la niñez en sectores afectados por la pobreza estructural, la desigualdad y la precariedad laboral?

Echarri Cánovas y Pérez Amador (2007) y Saraví (2009) plantean que existen varios «marcadores» de la juventud que representan pasos cruciales en el proceso de ganar autonomía y hacerse adulto: «a) la transición del sistema educativo formal al mercado de trabajo; b) la formación de una nueva familia a través de la unión conyugal y/o paternidad/maternidad; c) la obtención de la independencia residencial a partir del abandono del hogar de los padres; d) la búsqueda y construcción de una identidad propia» (Saraví:36-37). Lo interesante es que en ambos autores destacan que tales eventos no se dan de manera ordenada a lo largo del curso de vida, no siguen la misma secuencia, no ocurren en el mismo momento y representan un proceso en el que el joven elige o se ve obligado a seguir una trayectoria que termina convirtiéndolo en adulto. Dicha referencia es sumamente fértil en la medida en que algunos autores sostienen que la juventud no halla referente empírico en sectores populares, en donde rápidamente se ingresa a la vida adulta. En efecto, Machado Pais (2007) entiende que los jóvenes más desfavorecidos transitan hacia la vida adulta en un camino poco claro, con un fuerte grado de indeterminación hacia el futuro, lo cual torna problemático el hecho de hablar de transiciones hacia la vida adulta en sociedades en donde los rituales específicos que indicaban el camino hacia la adultez han perdido peso. En línea con lo argumentado por Saraví, consideramos que si bien es cierto que en tales sectores estos ritos y/o eventos habitualmente han perdido peso y/o se experimentan de manera más temprana que en otros, hay situaciones que indicarían la existencia de un período intermedio de transición. 
De acuerdo con ello cabe hacernos las siguientes preguntas: ¿Bajo qué circunstancias se encuentran hoy aquellos niños que vieron transcurrir su infancia en una situación doblemente desventajosa tanto por su condición de pobres y de trabajadores infantiles? ¿Qué eventos dan cuenta de las transiciones desde la niñez? ¿Cómo se experimenta dicha transición? ¿Qué particularidades presentan los patrones de transición - siguiendo el modelo propuesto por Saraví - en este grupo de sujetos? ¿Qué sucede cuando los eventos que marcan la transición de la juventud a la adultez se dan de manera temprana? ¿Se desarrolla un pasaje directo de la condición de niño a la de adulto? O bien, ¿se puede pensar a la juventud como un período más breve en la vida de las personas que viven en condiciones de pobreza? ¿Cómo se autodefinen? ¿Cómo jóvenes o adultos? ¿Qué diferencias se encuentran entre sus vivencias actuales y sus vivencias durante la niñez?

\section{EL CAMINO METODOLÓGICO ESCOGIDO}

Las preguntas que recorren esta investigación serán respondidas desde un abordaje cualitativo, a partir del análisis de un conjunto de relatos biográficos recuperados a través de entrevistas en profundidad desarrolladas en distintos momentos de la vida de los sujetos estudiados: un primer momento claramente situado en la infancia y un segundo momento ubicado en la juventud. ${ }^{6}$ De este modo nuestro trabajo se enmarca en los llamados estudios longitudinales. Recordemos que cuando se estudia un fenómeno en el tiempo se debe definir si el proceso a estudiar se toma desde su origen hasta el presente - estudios prospectivos-, o desde el presente hacia el pasado — estudios retrospectivos- (Muñiz Terra, 2012). En nuestra investigación nos hemos inclinado por el desarrollo de un estudio prospectivo. Vale aclarar que los mismos habitualmente se utilizan cuando lo que interesa conocer es cómo se produce la transición en el transcurso de un período determinado y cómo los sujetos responden frente a las rupturas que se presentan en tales momentos.

6 Ambas categorías fueron operacionalizadas de acuerdo con un criterio etario. Dados los fines de la investigación, se siguió el criterio que prima en la sociodemografía: en el caso de la infancia se consideró como niños al grupo comprendido entre los cinco y catorce años de edad, y para la juventud es decir, el grupo comprendido entre los quince y veintinueve años de edad. 
Un aspecto valioso de este tipo de estudios es que permiten ver qué características asumen las prácticas y representaciones sociales a lo largo del tiempo observando cómo se van ajustando - o no- al contexto, a la vez que habilita a que los sujetos puedan desarrollar nuevas miradas sobre su situación anterior desde la posición actual y que pueda evidenciarse lo ocurrido finalmente con aquello que se proyectaba a futuro.

La característica inicial que compartían los sujetos entrevistados era su pertenencia a sectores pobres estructurales, pertenecientes a núcleos familiares atrapados en numerosos círculos de desventajas - viviendas emplazadas en un territorio urbano segregado cuyas condiciones materiales eran sumamente deficitarias; padres sin empleo, con empleos precarios o informales que presentaban a su vez severas deficiencias en las credenciales educativas, ingresos escasos, etcétera-. Estos niños, integraban familias profundamente afectadas por procesos de privación y acumulación de desventajas.

Las entrevistas llevadas a cabo en el período definido como infancia se condujeron entre 2005 y 2008. En aquel momento, la selección de los casos a entrevistar estaba orientada a identificar a aquellos niños que desarrollaran actividades laborales; es decir, interesaba indagar las particularidades que adquiría la experiencia de ser niño y trabajador bajo condiciones de extrema pobreza. Ahora bien, el foco no estuvo puesto solamente en describir un ámbito particular de la existencia como es el trabajo, sino que en todo momento buscamos articular tales experiencias con el análisis de la esfera familiar, educativa y de la sociabilidad. Las entrevistas desarrolladas en el período definido por nosotros como juventud se llevaron a cabo en 2013. ${ }^{7}$ En esta oportunidad también inda-

7 El contacto inicial para comenzar el acercamiento a los chicos y sus familias fue gradual, incluyó una primera conversación - primero con los padres y luego con ellos - intentando ver si nos recordaban, buscando «romper el hielo», y volver a entrar en confianza. Las preguntas de la conversación dirigidas a los adultos incluían aspectos relacionados con su situación actual, la de los hijos, la detección de modificaciones en la composición familiar, la situación laboral de los adultos del hogar, etcétera Luego preguntábamos por el hijo/a que queríamos volver a entrevistar, algunos permanecían en el hogar paterno, y otros ya habían conformado sus propios hogares fuera de la vivienda de los padres. Según el caso, o intentaba contactar al joven en el hogar de sus padres, o buscaba contactarlo en su nueva residencia. Una vez hallado, manteníamos - al igual que con los padres - una conversación informal, preguntando si nos re- 
gamos sobre los mismos ámbitos de la existencia, manteniendo bloques de preguntas similares a las del primer acercamiento - consideradas a lo largo del tiempo: pasado, presente y futuro- pero el interés analítico se focalizó en el estudio de las transiciones desde la niñez. Para ello se incorporaron además preguntas orientadas a detectar las particularidades relativas a su nuevo estatus. ${ }^{8}$

Cabe destacar que en ambas oportunidades tanto con niños, jóvenes como con adultos tuvimos algunas dificultades para trabajar precisiones temporales en relación a los momentos en que sucedían los eventos sobre los que los interrogábamos. Probablemente - y esto es una hipótesis a profundizar - esto sea producto de un modo de habitar la temporalidad particular. Dada esta característica, el trabajo complementario con algún tipo de calendario de eventos resultó prácticamente imposible.

Como planteamos en la introducción, dado que se trata de una investigación en curso, elegimos trabajar con un número acotado de casos, que pudieran dar algunos indicios de la heterogeneidad con que pueden desarrollarse las transiciones desde la niñez. En este sentido cabe destacar que no se trata de una muestra definitiva que haya alcanzado su punto de saturación (Valles, 2007), sino que lo que proponemos es una primera aproximación al tema.

cordaban y repitiendo las mismas preguntas realizadas a los adultos. En ciertos casos este procedimiento lo repetimos dos o tres veces. Tanto a los padres como a los chicos/as los interrogábamos para ver si recordaban las entrevistas que hicimos años atrás. Si la respuesta era afirmativa, comentábamos que lo que se buscaba en esta oportunidad era conocer qué pasó con sus vidas pasados todos estos años, que cuando los conocimos eran «chicos», y que ahora eran más «grandes», y en ese marco es que nos gustaría saber qué cosas están haciendo, cómo están sus vidas hoy en relación a la escuela, el trabajo, la familia, etcétera. A partir de esta breve presentación de los objetivos y de esta charla «introductoria», se procuraba concretar una fecha y un horario de entrevista.

8 Se indagó además al respecto de a) Conformación familiar: presencia o no de cambios en la familia de origen (muertes, nacimientos, miembros nuevos de la familia, miembros que no están más), conformación o no de una nueva familia; b) Vínculos amorosos: presencia o no de una pareja, tipo de vínculos, forma en que se conocieron, expectativas sobre la pareja, en qué momento se conocieron, bajo qué circunstancia, presencia o no de hijos; c) Cambios residenciales: conformación o no de un nuevo hogar en una vivienda diferente a la de los padres; y d) Visión de la juventud/adultez: diferencias entre ser niño, joven y adulto, cómo experimentan el presente, cómo se ven a sí mismos. 


\section{LA ARGENTINA DEL SEGUNDO MILENIO: DE LA CRISIS A LA RECUPERACIÓN ECONÓMICA}

Ciertas características de orden sociohistórico no pueden evadirse al momento de dar cuenta de las transiciones desde la niñez en la Argentina «posneoliberal». Si como planteamos anteriormente, la perspectiva del curso de vida considera la interrelación entre las vidas individuales y la estructura de oportunidades, caben algunas observaciones al respecto del caso Argentino. ${ }^{9}$

En el período estudiado, que abarca prácticamente diez años, nuestro país comenzaba a salir de una profunda crisis económica (20012002) con severas consecuencias sociales. Sin lugar a dudas que durante el período de gobierno Kirchnerista la recuperación económica trajo aparejada un importante descenso del desempleo y la pobreza. «Entre los años 2002 y 2007, la Argentina ha transitado un período que se ha caracterizado por una serie de novedosas e inéditas dinámicas en lo que refiere a sus principales indicadores económicos. No solo se han alcanzado récords en materia de tasa de empleo, producto bruto interno, producto bruto industrial, exportaciones industriales, peso de las exportaciones en el producto industrial, sino que, lo más llamativo de todo, esto se ha producido de manera casi inmediata tras la peor de las recesiones que recuerde su historia» (Varesi y Pinazo, 2011:35).

No obstante ello, tal como argumentan Kessler y Merklen (2013) esa recuperación esconde un hecho fundamental y es que el empleo estable y protegido aún resulta inaccesible para buena parte de los sectores populares, siendo una enorme causa de sufrimiento. Para vastos sectores de la población «la experiencia popular se estructura así, para muchos, sobre varias generaciones que nunca se beneficiaron de la integración al salariado estable. De un modo mucho más extendido, el horizonte de los jóvenes - es decir, de aquellos que pugnan por llevar una vida autónoma o formar una familia, criar a sus hijos, ingresar en la vida adulta y en el mercado de trabajo-, se proyecta masivamente hacia la experiencia de la inestabilidad» (Idid:14).

En un trabajo en el que se abordan distintas situaciones de inclusión respecto del sistema educativo y el mercado de trabajo en jóvenes

9 Cabe aclarar que aquí haremos una breve referencia a dicho período, a modo de panorama general, sin detenernos en análisis pormenorizados de datos. 
de quince a veintinueve años de edad, ${ }^{10}$ se argumenta que pese al actual contexto de bonanza económica, que presenta una mejora en los indicadores laborales y económicos y una expansión de las credenciales educativas de nivel medio, el sistema económico y social de nuestro país, está lejos de haber logrado un cambio cualitativo en lo que hace a la inclusión social de los jóvenes (Bonfiglio, Salvia, Tinoboras y Van Raap, 2008).

En concordancia con el diagnóstico desarrollado por los autores mencionados, estamos en condiciones de afirmar que la población que ha sido objeto de nuestro estudio forma parte de un núcleo duro de pobreza que no solo no se ha visto beneficiada de la integración a un empleo estable - con todas las consecuencias que ello acarrea-, sino que también se ha visto envuelta en una espiral de acumulación de múltiples desventajas, engrosando la fila de la «población vulnerable» (Castel, 2000). Como sostiene Saraví (2007), quien sigue el planteamiento de Fitussi y Rosanvallón, a las desigualdades estructurales o permanentes de las que son víctimas vastos sectores de la población, hay que sumarles un nuevo tipo de desigualdades, de carácter dinámico, caracterizas por su transitoriedad y por su tendencia a fijarse en las trayectorias biográficas. En América Latina «la especificidad reside precisamente en que sobre desigualdades estructurales que no sólo no pierden fuerza sino que se profundizan, emergen desigualdades de trayectorias que incrementan la vulnerabilidad de la construcción biográfica, que fragmentan las categorías de clase o status con múltiples patrones biográficos y que plantean el riesgo de la exclusión. El curso de vida, y en particular, las trayectorias biográficas, constituyen la unidad de análisis en que accidentes o eventos aleatorios pueden constituirse o en desigualdades desencadenantes o en nuevos engranajes de procesos de acumulación de desventajas» (Ibid:34). A continuación veremos qué particularidades adquieren estos procesos en las biografías de los sujetos entrevistados.

\section{EL PUNTO DE PARTIDA: UNA INFANCIA PROFUNDAMENTE AFECTADA POR LAS PRIVACIONES}

La característica inicial que compartían los entrevistados era la pertenencia al grupo de pobres estructurales, profundamente afectados por

10 Tomando como base datos del total de aglomerados urbanos relevados por la Encuesta Permanente de Hogares en el segundo semestre de 2006. 
procesos de privación. Además de condiciones de vida en la pobreza de larga data, a ello se sumaba una característica peculiar: una temprana inserción en el mundo del trabajo. La mayor parte de ellos desarrollaba sus actividades laborales en el espacio público, dedicándose al «cirujeo» o «trabajo en el carro» y a la mendicidad y/o actividades que la acompañan como la venta de flores, de estampitas y la limpieza de los parabrisas de automóviles.

Las vidas de estos niños estaban dominadas por lo aleatorio, y el rumbo que iban tomando estaba en gran parte condicionado por las circunstancias en las que sus familias se hallaban inmersas, especialmente dos de ellas nos parecen clave y también definitorias en lo que fueron sus primeras incursiones en el desarrollo de actividades laborales. Una, la situación conyugal del hogar (conformación de familias nucleares o incompletas). Otra, la realidad económica de los miembros de la familia: distintas fuentes de ingresos monetarios y no monetarios con que se contaba en el hogar. De acuerdo a cómo se combinaban estos factores la intensidad y temporalidad de las inserciones laborales de estos niños iban variando.

Si bien acordamos con el planteamiento de Saraví (2009) al respecto de que la juventud representa un período crítico y de vulnerabilidad en lo que atañe a los procesos de acumulación de desventajas, las transiciones desde la niñez también lo son y su estudio puede representar también un buen punto de partida.

Creemos importante destacar dos datos en lo que atañe a procesos relacionados con modificaciones en la estructura de oportunidades que han incidido, y en parte modificado, aspectos relacionados a las condiciones de vida de los sujetos al ser entrevistados por segunda vez. Por un lado el acceso a uno de los pilares de la política Kirchnerista como lo son las transferencias condicionadas a través de la Asignación Universal por Hijo (AUH). ${ }^{11}$ Por otra parte, el acceso al Plan Federal de

11 Tomando como base datos del total de aglomerados urbanos relevados por la Encuesta Permanente de Hogares en el segundo semestre de 2006.

12 «Es un beneficio que le corresponde a los hijos de las personas desocupadas, que trabajan en el mercado informal o que ganan menos del salario mínimo, vital y móvil. Consiste en el pago mensual de $\$ 460$ para niños menores de 18 años y de $\$ 1.500$ para chicos discapacitados sin límite de edad. Esta asignación fue creada por medio del decreto Nro. 1602/09, del Poder Ejecutivo Nacional, y comenzó a regir a partir del $1 / 11 / 09$. Con la misma, el Estado busca asegurar que los niños y adoles- 
Viviendas (PFV), ${ }^{12}$ al que entre los años 2006 y 2008 pudieron incorporarse una parte importante de las familias que han sido objeto de la investigación, quienes fueron relocalizados en las inmediaciones de la zona. Dicho plan provocó una modificación tanto en el entorno como en las condiciones habitacionales, o sea, el hábitat cambió sustancialmente desde que comenzaron a contar con viviendas y condiciones urbano-ambientales diferentes. Tanto el acceso a nuevas condiciones habitacionales como a la AUH no pueden dejar de pensarse como dos datos objetivos relacionados con nuevas formas de intervención del Estado sobre los sectores más desfavorecidos que han incidido en la vida de los sujetos.

\section{a) Las vidas de Sandro, Tano, Melina y Melisa Sandro y el trabajo como «rescate»}

Cuando entrevisté a Sandro por primera vez tenía diez años, hoy tiene dieciocho. En ese entonces vivía en una casa muy pequeña y precaria - con partes de la construcción en material y partes en chapa y madera- junto a su madre y sus tres hermanos menores. De manera intermitente vivían con ellos algunos de los hermanos de su madre.

El primer punto de quiebre que marcó una redefinición en su curso de vida fue la separación de los padres, cuando tenía cinco años. Su

centes asistan a la escuela, se realicen controles periódicos de salud y cumplan con el calendario de vacunación obligatorio, ya que estos son requisitos indispensables para cobrarla. Actualmente, más de 3.500 .000 chicos y adolescentes son beneficiados con esta asignación». Información extraída de: www.anses.gob.ar.

En un intento por «revisar» la problemática de la vivienda, en el año 2004 el gobierno nacional lanzó en nuestro país un Programa Federal de Construcción de Vivienda. En un documento oficial se sostiene que los objetivos del programa son: consolidar la evolución habitacional y fortalecer el proceso de reactivación económica, proponiendo la construcción de 120.000 viviendas en todo el país, de las cuales 33.000 se edificarían en el Gran Buenos Aires. Dentro de este programa se encuentra el Subprograma de Urbanización de Villas y Asentamientos Precarios que es el que se ha desarrollado y continúa - ya que aún no ha concluido- en el barrio estudiado. El mismo incluye la relocalización de los vecinos en nuevas viviendas en áreas sobre las que se han dado una serie de transformaciones como la provisión de asfalto, cloacas, alumbrado público, espacios verdes y equipamientos en educación. 
padre dejó el hogar y con ese abandono también se resquebrajaron los vínculos de él con sus hijos, con quienes desde ese entonces no ha mantenido contacto. Del padre poco se sabe o más bien poco se dice. Su madre apenas pudo concluir la escuela primaria, y también ha trabajado, pero en su caso desde los once años y durante la adolescencia. El abandono de su padre - que en el plano emotivo lo afectó profundamente - tornó la situación económica del hogar aún más crítica, ya que él era el único que aportaba ingresos monetarios, y es en ese marco que su madre decide «salir a la calle» con sus hijos, primero a mendigar y luego a trabajar, durante un tiempo como «ciruja» y luego instalándose de manera regular en calles transitadas de la ciudad en la que sus hijos alternaban actividades como la venta de flores y la limpieza de los vidrios de los automóviles que detenían sus vehículos en el semáforo:

R: Sandro desde que yo me separé es así.

P: ¿Desde que te separaste del papá de él?

R: ¡Claro! Del papá de ellos, el Sandro es como que...tomó una... ¿cómo te puedo decir? Se hizo un poquito más hombrecito solo.

P: ¿Y por qué? ¿Por qué más hombrecito?

R: Porque él era un nenito del papá, al separarse del papá eh [...] el papá al dejarlo se tuvo que adaptar al... a... a estar solo, a estar conmigo nomás, a criarse solito, conmigo, es como que es [...] un nenito que tiene muchas responsabilidades para él .

P: y $[\ldots]$ y qué responsabilidades porque me decís responsabilidades $[\ldots]$ ¿en qué sentido?

R: En el sentido que él sabe que si no vamos a vender flores no come, si él no va en el carro los hermanitos no comen, por eso, una responsabilidad muy grande tiene él» (madre de Sandro, año 2005).

En este contexto, la condición de la madre de Sandro como mujer sola reforzó la vulnerabilidad y las condiciones de vida críticas de los miembros del hogar, ya que no sólo la sobrecarga de actividades y responsabilidades era mayor para ella, sino que también se trasladó a los hijos - sobre todo al mayor-, quienes asumieron el compromiso de obtener los bienes o ingresos necesarios para sostener a la familia. Varios estudios dan cuenta de que «las mujeres que son jefas de familia sufren una gran desventaja en el mercado de trabajo. Ellas tienen niveles más bajos de educación y responsabilidades familiares más pesadas, que frecuentemente las restringen a empleos en el sector informal» (Safa, 1994:39). En nuestro caso, ni siquiera han conseguido 
empleo, sino que durante la infancia de Sandro, su labor consistía en acompañarlo en la realización del trabajo. Desde aquel momento hasta hace algunos meses atrás, Sandro ha trabajado siempre en el mismo tipo de actividad: en la calle, limpiando vidrios o vendiendo estampitas, y lo ha hecho a un ritmo intenso: seis veces por semana durante varias horas. El trabajo en la calle lo llevó a conocer muchas personas, entre ellas algunos amigos que lo introdujeron en el mundo de la droga desde los diez años de edad:

R: Me drogaba mucho [...] desde los diez años, por un amigo de la calle $[\ldots]$ pasa que en la calle encontrás de todo [...] salía todas las noches, me drogaba todo el día, no comía [...].

Ahora bien, el segundo punto de inflexión en su vida acontece hace relativamente poco, cuando accede unos meses atrás por primera vez a un trabajo de otras características: la recolección municipal de basura, que parece reconstituirlo como sujeto y alejarlo de ese pasado tan destructivo:

R: Me vino al pelo, estoy todo el día laburando.

P: ¿Estás conforme?

R: Sí. Salí de la joda, de todo.

P: ¿Estabas en la joda?

P: Sí, me compré una moto, me compré el celular [...] yo siento que tengo, mi plata, no la saco de ningún lado, la gano [...] me las compro yo mis cosas como tiene que ser $[\ldots]$ no pido nada a nadie $[\ldots]$ a veces pido, a veces no $[\ldots]$

P: ¿Y porqué yo no salís más?

R: Porque conseguí el laburo éste [...] me rescaté mucho por el laburo.

P: Ah. A partir de que conseguiste este laburo para vos, ¿sentís que hubo un cambio?

R: Sí, un cambio de vida.

P: Un cambio de vida [...] y ¿te seguís drogando o?

R: Como, como todos los días, antes no comía nada [...] No, estaba todo el día drogándome, pero ahora como, como, me baño, me cambio, como y me voy a trabajar y al otro día hago lo mismo, como, me baño y me acuesto a dormir...

P: Y te acostás a dormir, ¿así es tu día?

R: Ś́, y me siento feliz [...]

A raíz de esta nueva posibilidad que se abre en términos de una inserción laboral diferente, al menos valorada y reconocida como menos 
precaria a la anterior, subjetivamente siente que su vida da un giro de 360 grados. Este nuevo trabajo - al que accede como cooperativistale permite «salir de la calle» con todo lo que ello implica: le impone una rutina, un cambio de contexto -que lo ayuda a salir de la adicciónen la medida en que pasa mucho tiempo solo, alejado de los amigos, y lo habilita a un consumo antes vedado. Mientras que desde niño lo recaudado como limpiavidrios prácticamente se destinaba en su totalidad a cubrir las necesidades alimentarias del hogar, con este nuevo ingreso regular, de 2.000 pesos al mes, ${ }^{13}$ una parte se destina a cubrir las necesidades de consumo familiar, mientras que otra se reserva al consumo personal.

$\mathrm{El}$ acceso a un trabajo con un ingreso regular y desarrollado por fuera de la esfera familiar aparece aquí como un medio que posibilita una mayor autonomía, una salida de la droga y un acceso a cubrir necesidades personales - muy asociadas a la condición juvenil-que de ningún modo podían ser financiadas por su madre.

La posibilidad de ingresar en esta nueva actividad ha venido de la mano de un cambio en su estructura familiar, ya que después de varios años, su madre volvió a tener una pareja estable —con la que ahora tiene un bebé- $-\mathrm{y}$ es esta nueva persona que ingresa en sus vidas la que habilita su red de contactos para que Sergio consiga un trabajo allí, donde él mismo se desempeña. Asimismo también su madre logró ingresar en una cooperativa municipal para la que trabaja barriendo las calles. Pareciera ser que con la nueva conformación familiar se produjeron ciertos cambios positivos y reordenadores para la vida de Sandro y los demás miembros de la familia.

$\mathrm{Al}$ interrogarlo por las diferencias que encuentra entre su pasado y su presente cometa:

No, no te lleva a nada el recuerdo, casi no te lleva a nada, yo por eso conseguí un laburo y lo que no me pude comprar de chiquito me lo compro ahora. Que no tenía nada antes, a los ocho, a los diez año no tenía nada, ahora, recién ahora estoy manteniendo mi casa, me falta comprarme muchas cosas $[\ldots]$.

En lo que respecta a la escolaridad, como buena parte de la literatura sostiene, el trabajo compite generalmente con el espacio escolar, provocando muchas veces la convivencia de ambos o planteándose una ruptu-

13 Para tener una aproximación al valor de la moneda argentina, un dólar es el equivalente a 6,15 pesos argentinos. 
ra: se sigue un camino u otro. Si bien en el caso de Sandro el abandono escolar se dio tempranamente - asistió hasta cuarto grado- durante algunos años el trabajo y la escuela primaria convivieron, aunque con una particularidad: las sucesivas repitencias, fundamentalmente ligadas al ausentismo que finalmente derivaron en un tempranísimo abandono.

A lo largo de su infancia, la escuela fue finalmente desplazada por el trabajo. Actualmente tiene la expectativa de volver a la escuela, de hecho ya conversó con la directora del colegio del barrio para averiguar cómo podía reinsertarse. El mayor incentivo para retomar deviene del impulso que le da el hecho de que algunos de sus tíos, primos y hasta su madre quieren retomar los estudios. El ir todos juntos parece ser algo sumamente motivante, no mencionando nada respecto de las potencialidades de la educación formal como habilitadora de nuevas y mejores perspectivas a futuro.

El futuro cercano que por el momento proyecta es el reingresar a la escuela y poder construir su propia vivienda en el mismo terreno en el que vive con su madre, de modo tal que pueda lograr una relativa independencia residencial. Sus esfuerzos por ahora se dirigen hacia esa meta orientada a la emancipación de su familia de origen.

Si recuperamos las cuatro transiciones clave de las que nos hablaba Saraví (2009), Sandro ha transitado desde la niñez por una de ellas: la salida de la escuela y el ingreso al mundo del trabajo. Por el momento sigue ocupando en su familia el lugar de hijo: aún no se ha independizado de la residencia familiar, no ha formado una familia y se identifica con lo juvenil. Si bien al comparar pasado y presente las coordenadas temporales de su «aquí y ahora» (Schutz, 2003) lo llevan a experimentar en su juventud una vida mucho mejor que la de su infancia, él sigue igualmente atrapado en un mundo del trabajo caracterizado por la precariedad, sin las mínimas credenciales educativas necesarias para aspirar a empleos más calificados — con las escasas oportunidades de movilidad social ascendente que este cuadro de situación conlleva - Paralelamente, si bien su familia ha accedido a las viviendas del Plan Federal, ellos continúan viviendo en un barrio segregado, y sus ingresos siguen sin alcanzar la meta de la satisfacción de las necesidades más básicas, pese al acceso de su madre a una cooperativa en la que gana 1.200 pesos mensuales, el ingreso que ahora suma su nueva pareja, etcétera. 


\section{b) Tano y la conformación de una nueva familia}

Tano tiene actualmente diecinueve años. Trabaja, ha constituido hace tres años y medio su propia familia - integrada por su compañera y su pequeño hijo - ha obtenido su independencia residencial; es decir, ha abandonado la vivienda paterna para conformar la propia y ha dejado la escuela muy tempranamente, en segundo grado.

Su madre y su padrasto - a quien considera su padre - migraron en 2002 desde Cañuelas, ciudad integrada al Área Metropolitana de Buenos Aires - con la expectativa de encontrar en La Plata una vida mejor para sus hijos. En ambas ciudades se dedicaban y continúan haciéndolo al cirujeo, actividad que en los primeros tiempos era realizada con sus hijos mayores: Cristina y Tano, y a la que luego se incorporaron los dos más pequeños.

Algo característico en la familia era la disciplina con la que llevaban adelante su trabajo: días y horarios fijos establecidos, división eficiente del trabajo según criterios de género y edad, etcétera $\mathrm{Al}$ referirse a Tano, su padre comentaba:

R: Tengo que hacer una cosa estricta que él no quiere ir, es redifícil a veces. Siempre sale conmigo, en el carro, él es el que hace todo; el que viene y prepara todo...después anda bien, el se divierte como un chico pero a su vez es responsable [...] para los once años que tiene es muchísimo.

P: ¿Por qué me decís que es muy responsable?

R: Y, porque él tiene que ser responsable, un pibe de once años tiene que ser responsable. Es cómo lo eduques al chico y como le aprendes; si yo le digo al nene, si yo lo acostumbro «ah pobrecito» son las diez y está durmiendo, son las doce [...] y recién se levanta a esa hora pueden comer los gusanos, no queda nada en las casas ni para darle a mis hijos chiquitos. Quizá que yo vine con ganas de trabajar y encontrar algo más mejor para mi hijo, lo encontré acá, acá encontré muchas cosas ¿entendés? Viví muchas cosas y veo muchas cosas malas que no vi en otro lado» (Papá de Tano, 2004).

Tano trabaja de manera ininterrumpida desde que tiene cinco años y atribuye el abandono escolar a la necesidad de trabajar. Si bien cuando era pequeño salía a trabajar con su padre, a medida que fue transcurriendo el tiempo, fue adquiriendo mayor independencia para desarrollar sus actividades laborales. Igualmente, mientras vivió en el hogar paterno, los ingresos obtenidos de su trabajo no se individualizaban, 
sino que se compartían con el resto de los miembros del hogar, siendo los adultos quienes disponían de ellos. Habitualmente se utilizaban para afrontar los gastos corrientes del hogar, como la compra de alimentos y vestimenta.

Todos estos años de su vida trabajó como «carrero», salvo en algunos períodos en que desarrolló exclusivamente otras actividades laborales o combinó el cirujeo con otros trabajos - situación en la que actualmente se encuentra-.

$\mathrm{Su}$ recorrido laboral está plagado por sucesivos ingresos al mundo de la extrema precariedad y la informalidad laboral: hizo «changas»; manejó un colectivo en el mercado de frutas y verduras - colindante al barrio-; trabajó en algunos depósitos de la zona; es decir, en los lugares de compra y venta del papel, cartón y metal, recuperado por los cartoneros. Desde hace cuatro años trabaja en un depósito del barrio, en el que ha ido asumiendo distintas responsabilidades: desde la carga y descarga de mercadería, pasando por la clasificación hasta el transporte en camión de la mercadería hacia el conurbano. Vale aclarar que como transportista se ve expuesto a un importante riesgo ya que además no cuenta con el carnet de conductor. A veces — según la intensidad requerida - trabaja seis u ocho horas por día, pero generalmente pasa allí entre diez, catorce y hasta veinte horas diarias, lo cual hace que el trabajo se vuelva cuesta arriba, a lo que se suma el dolor físico, principalmente en la columna por el tipo de esfuerzos que ha hecho a lo largo de su vida.

Con las actividades que desarrolla en el depósito gana 150 pesos diarios - cuando el patrón no se retrasa en el pago porque no tiene dinero suficiente para efectuarlo- que son destinados a los gastos alimentarios. Lo que él y su pareja reciben de la AUH, lo destinan exclusivamente a todo lo que precisa su pequeño hijo (la medicación para el asma, ropa, pañales, etcétera). El dinero que logra reunir los días que sale en el carro lo utiliza en parte para el mantenimiento del caballo y también para gastos corrientes en alimentación.

Desde hace tiempo está evaluando abandonar el depósito, para dedicarse exclusivamente al cirujeo, ya que le deja más dinero, consigue más cosas - comida, ropa, muebles - trabaja menos horas, dispone de los horarios y siente menos dolor físico. Lo que aún lo ata a ese trabajo es su vínculo con el patrón, con quien siente que mantiene cierta deuda afectiva ya que frente a algunas situaciones críticas que le han tocado vivir, principalmente vinculadas con sucesivas internaciones de su hijo, el patrón lo ha ayudado — con dinero, permitiéndole faltar al trabajo, etcétera- 
Como no es difícil intuir, el dinero que tienen apenas les alcanza para sobrevivir, y pese a que su pareja expresa interés por trabajar, fundamentalmente para incrementar los ingresos del hogar, él se resiste a esta idea, arrastrando un patrón tradicional machista en cuanto a la división del trabajo en el hogar.

Desde su niñez, Tano ha quedado atrapado en un mercado de trabajo sumamente precario, con escasas expectativas de poder salir de allí. En los distintos momentos de su vida en que lo hemos entrevistado se encargó de enfatizar que ninguno de los trabajos realizados lo han satisfecho, que con ninguno de ellos se siente o se ha sentido a gusto.

Años atrás, aspiraba a trabajar como mecánico, hoy, su máxima aspiración a futuro es obtener un empleo como chofer, ya que le agrada manejar, pero esta posibilidad también se ve doblemente limitada: no posee carnet de conductor - no tiene dinero para poder obtenerlo- y no ha completado sus estudios.

Su breve tránsito por el espacio escolar es reconocido por él como una gran limitante en relación a su presente y su futuro laboral. En el imaginario de Tano sigue existiendo un pleno ajuste entre las posibilidades de mejores inserciones laborales y la conclusión de los estudios. Si bien años atrás la opción de retornar la escuela no era vislumbraba, actualmente, y en parte por el gran estímulo que su pareja ofrece, y por las nuevas ofertas educativas que facilitan la terminalidad escolar, está reconsiderando la posibilidad de volver a estudiar.

La constitución de su pareja y la llegada de su hijo son vividos como un punto de quiebre en su vida, evaluado positivamente. Incluso es lo que le ha facilitado la salida del mundo de la calle y la droga, compartido con sus pares:

Y cuando yo me junté con ella agarré y ya no...no me llamaba tanto la atención salir a la calle [...] me quedaba más qué sé yo, por ahí íbamos a una plaza con ella y tomábamos un helado o íbamos al centro a caminar...entonces ya, ya no me llamaba tanto la atención...por ahí me fumaba un cigarro y se me pasaba las ganas de fumar que tenía [...].

La conformación de una familia y la salida de la casa de los padres a edades tempranas es en sectores pobres algo que forma parte de su horizonte normal de posibilidades, aunque esto no implica que una transición familiar y residencial tan temprana no acarree riesgos. En el caso de esta pareja parece no haber habido una planificación familiar, ellos se conocieron, y al poco tiempo se encontraban viviendo juntos y 
esperando un hijo. La independencia residencial se vuelve efectiva unos meses después de iniciada la convivencia. Previo a apropiarse de un terreno y poder comprar una casilla - sin piso, con techo y paredes de chapa en la que no hay acceso a la red de agua, etcétera- vivieron un tiempo en una casa que un amigo les prestó y luego en la casa del padre de Tano, quien se benefició de las viviendas otorgadas por el Plan Federal.

Con tan solo diecinueve años parece haber completado todos los marcadores de la transición a la adultez de manera muy temprana, logrando una plena autonomía de la esfera parental, algo propio del modelo hegemónico de la edad adulta. No obstante ello, se ve y se piensa a sí mismo como un joven.

\section{c) Melina y la vivencia de un presente menos sufrido}

Melina es hoy una joven de diecisiete años, la mayor de siete hermanos. Vive con sus padres, hermanos y cuñado - novio de la hermana que le sigue - en una vivienda entregada por el Plan Federal. Para ella, el acceso a esta nueva vivienda ha marcado un cambio importantísimo en sus condiciones de vida, fundamentalmente asociada a las comodidades del entorno «más tranquilo, sin tanto quilombo», el mayor espacio y la calidez que cualquier construcción de material brinda por sobre el frío padecido en las casillas en las que antes vivían.

Durante su infancia ha tenido una vida muy dura, con problemas de desnutrición y jornadas extensas de trabajo, tanto en las tareas del hogar, con un intensísimo ritmo, como en actividades ligadas a la mendicidad y el cirujeo. Ya, a sus ocho años de edad era llamativo el nivel de responsabilidad asumido para afrontar las necesidades más básicas de su hogar. Recuerda haber cirujeado hasta los trece años de edad aproximadamente, momento en el cual su padre accede a un empleo en el zoológico de La Plata y abandona el cirujeo. No obstante ello, de manera intermitente continuó trabajando: cuidó niños, hizo trabajos de albañilería y electricidad con su padre, repartió volantes y salió circunstancialmente a «manguear» cuando en su casa faltaba la comida.

R: Trabajé en el carro hasta los [...] trece, catorce años, no más, porque mis papás no quieren que salgamos más en carro ni a manguear porque no quiere esa vida para nosotros, quiere una mejor vida [...] estaba cansado, para nosotros quiere lo mejor, siempre lo va a querer pero a veces si no hay para comer por más que nos diga 
[...] es más, vemos que cuando no mangueamos, nos agarramos la cabeza porque mi papá no nos dejaba manguear y veíamos cómo tiraban la comida, comida que gente por ahí necesita, viste [...].

P: ¿Y qué cosas mangueaban?

R: Vamos y mangueamos, suponte, nos metemos a las carnicerías, mangueamos, nos dan carne, a la verdulerías, nos dan verdura, a coso de pastas [...] nos escapamos y vamos a manguear igual [...] y a veces nos traíamos carne, factura y a la heladería, también (risas), para comer helado, eh, ahora, encima también mangueamos casa por casa, si pregunto casa por casa yo tengo un par de amigas pero hay una que esa, más que nada mi amiga y siempre cuando necesité algo me dijo que vaya, ahora yo hace rato no pasé y tengo que pasar porque ella siempre me, una vez me regaló plata para comprarme zapatillas y me compró zapatilla y siempre me da mercadería [...].

Los ingresos obtenidos en sus distintos trabajos siempre se los ha dejado a su madre, para que disponga y administre de acuerdo a las necesidades del hogar. Su caso marca una diferencia con respecto a otros jóvenes que reservan al menos una parte de sus ingresos para satisfacer aquellas necesidades de consumo personal.

Si bien el acceso de su padre a un empleo municipal ha representando una mejora en la situación económica del hogar, los ingresos generados siguen sin ser suficientes, de hecho el novio de su hermana, que cohabita con la familia, carga con los gastos de su novia y aporta a la «olla familiar», al igual que el novio de Melina: «cuando... cuando no tenemos... cuando no tenemos o yo tengo hambre o algo agarra y va y compra o manda comprar $[\ldots] \gg$.

En relación con las perspectivas laborales hace mención al deseo que tanto ella como su novio tienen de «tener un trabajo fijo». La dificultad del acceso a un empleo de tales características la relaciona en parte a su condición de menor de edad, aspecto que lleva a pensar en las tensiones que generan el reconocimiento de nuevos derechos - como lo es el de no trabajar a edades tempranas-y las «realidades» de los sujetos.

Su tránsito por el sistema educativo si bien ha tenido cierta discontinuidad - por ejemplo, el año pasado tuvo que dejar por la incompatibilidad de la escuela con su trabajo de niñera- el ausentismo y la repitencia la ha acompañado en distintos momentos de su trayecto escolar. En 2013 estaría retomando el segundo año de secundaria, que precisa concluir para luego entrar en la universidad. Según la joven, los veterinarios del zoológico le facilitarían una beca para que curse sus estudios en la Facultad de Veterinaria: 
No igual por más que no tenga beca yo si no le decía, si no llego a conseguir beca yo cuando trabaje voy, o sea, antes de empezar la Universidad voy a trabajar y voy a juntar la plata para pagarme la Universidad, le decía yo a mi madre, y eso es lo que le emociona a mi madre de mí, mi empeño, mi empeño en estudiar y seguir estudiando, eh, sí o sí ir a la Universidad, desde, ir a la Universidad desde chiquita quise, desde muy chiquita, desde que empecé a ir a estudiar apoyo escolar que vi que podía aprender más, desde ahí, pero no estaba segura qué quería hacer pero como yo vi mi entusiasmo y mi emoción por los animales $[\ldots]$.

Dos cambios son los que ella percibe en su vida desde que abandonó la etapa de la infancia e inició su entrada a la juventud: uno, el mayor nivel de responsabilidad que año a año ha ido adquiriendo; el otro, la mejora relativa en las condiciones materiales de vida:

Ahora sí, porque ahora estamos mejor, ahora tenemos más ropa, mis hermanos tienen zapatilla, un montón, lo mejor es que los más chiquititos están viviendo una vida buena, más bien buena, no tanto como nosotros que más o menos algo sufrimos, de que a veces [...] antes no teníamos ropa o no teníamos zapatillas, no era tanto como ahora que ahora lo tenemos todos y cuando queremos, esta vez sí todo, todo [...] bueno casi, (risas) $[\ldots]$ a veces no hay para comer, pero bueno, mal o bien lo tenemos todo casi $[\ldots]$.

Pareciera ser que durante su juventud ha podido acceder a algunos de los «privilegios» que durante su infancia le habían sido vedados. Continúa ocupando el lugar de hija; es decir no ha iniciado una transición residencial y familiar temprana, no se ve en la obligación de trabajar tan duro como lo ha hecho durante su niñez, habita en una vivienda en condiciones muchísimo más dignas, accede a ciertos consumos antes impensados y puede pensar en un futuro próximo como estudiante universitaria.

\section{d) Melisa y la maternidad como punto de inflexión en su vida}

Melisa es una joven de quince años, que vive con su madre, el compañero de su madre y sus hermanos. Es la tercera de siete hermanos, hijos de diferentes parejas que ha conformado su madre. Si bien mantiene cierto contacto con su padre, el mismo es de carácter esporádico pues recurrentemente es apresado por robo, pasando en la cárcel buena parte de su vida. 
Su madre es de origen paraguayo, y el hecho de no contar durante mucho tiempo con la documentación legal de residencia en el país la ha trabado en el acceso a posibles empleos y diferentes tipos de beneficios estatales, que hubiesen servido para alivianar sus pésimas condiciones de vida.

Antes de conocer a su anteúltima pareja, en el año 2005, la realidad de la familia era bastante crítica. Vivían en una casilla sumamente precaria, ella era jefa de hogar, y no tenía oportunidades de conseguir inserción laboral alguna. Tras sucesivos intentos por generar ingresos, decidió salir a la calle junto a sus hijos a pedir.

Porque si yo los pongo ahí a ellos en dos horas me traen cinco pesos, si yo me pongo dos horas me van a pedir diez centavos. ¿Por qué no le dan a la gente grande? Si yo estoy dando la cara, diciéndote mi miseria ¿me ayudas? ¡No tengo para comer! Me ayudas a mí, ¿entendés? no a mis hijos, es así, tendría que ser así ¿o no? O voy con una escoba, una vez, antes de ir a 7 , fui con una escoba y una palita y un carrito a mano y yo golpeaba los timbres e iba diciendo si no podía barrer la vereda ahí y me decían no, no tengo nada, no tengo nada [...] (Madre de Melisa, 2005).

Como dijimos anteriormente esta situación crítica logró revertirse al formar pareja, quien facilitó mejores condiciones de habitabilidad - se trasladaron a una vivienda prestada, de material - e ingresos suficientes como para que ni ella ni sus hijos deban trabajar, en efecto eso era algo que molestaba profundamente a su pareja.

Si bien su padre y aquella pareja concluyeron su relación, de hecho él falleció hace dos años atrás, hoy las condiciones de vida para la familia difieren sustancialmente en sentido positivo. Su madre consiguió un empleo en las inmediaciones del barrio limpiando colectivos; accedió a las viviendas del Plan Federal — aspecto que garantizó la seguridad en la posesión de una vivienda - y sus hijos no se han visto desde entonces obligados a trabajar.

La particularidad que presenta la vida de esta joven es que cursa un embarazo no planificado de seis meses, hecho que ha «sacudido» su vida. Tras un noviazgo breve, de cuatro meses, con un vecino de veinte años de edad que habita una vivienda colindante a la suya, quedó embarazada y al poco tiempo fue abandonada. Un embarazo no deseado, a tan temprana edad ubica a esta joven en una importante condición de riesgo. Como sostiene Saraví (2009) la ocurrencia de embarazos antes de los veinte años es en sí mismo resultado de una situación de vulnerabilidad, y cuando en estas situaciones no intervie- 
ne la planificación, ni la decisión individual, sino más bien factores compulsivos se constituye en un factor de riesgo que probablemente desencadene sucesivas desventajas.

Aunque en su imaginario ella entiende que el hecho de ser una futura madre la ubica en un lugar de adulta y no de niña, sus prácticas hablan de una situación contraria: ella depende de los otros adultos del hogar - su hermana y su madre - para enfrentar diferentes cuestiones de la cotidianeidad: su hermana es la que la anota en la escuela, su madre es quien la lleva a la Unidad Sanitaria a hacerse los controles de salud, la acompaña a hacer trámites, le administra el dinero - de lo contrario ella sostiene que lo malgastaría- No tiene planeado abandonar el hogar de su madre, sin embargo sí están pensando en construir una casita para su bebé y ella en el mismo terreno, de modo de tener cierta independencia, pero estando cerca de su madre.

Desde que se enteró de su futura maternidad, procuró generar algún tipo de ingreso monetario, o en su familia la incentivaron para eso, y hace poco tiempo terminó consiguiendo un trabajo transitorio como niñera, cuidando un niño del barrio que vive a la vuelta de su casa. Por trabajar de lunes a viernes durante la mañana gana 300 pesos al mes.

El embarazo no ha sido un obstáculo para que continúe en la escuela, entendiendo que el paso por ella es la única oportunidad que tiene de obtener «un trabajo bueno». En el futuro aspira a ser policía, ese es su sueño. Ahora bien, durante todos estos años su recorrido escolar ha estado plagado de ausentismo reiterado y sucesivas repitencias.

En términos generales si bien en el período de tránsito desde la niñez las condiciones de vida de la familia han mejorado sustancialmente, su temprano embarazo parecen haberla hecho retroceder unos pasos atrás, potenciando su vulnerabilidad.

\section{REFLEXIONES FINALES}

A lo largo de este trabajo hemos procurado demostrar la pertinencia de indagar cómo se producen las transiciones desde la niñez en sectores pobres, y cómo éstas se incrustan en trayectorias vitales.

A la luz de los casos seleccionados para el análisis, si bien ellos dan cuenta de construcciones biográficas heterogéneas, hay un elemento común que los atraviesa: estos sujetos pese a vivir cierta mejora relativa en sus condiciones de vida, continúan estando profundamente afectados por restricciones de orden estructural, haciendo que sus vidas sigan invadidas - tal como en su infancia - por la precariedad. 
Creemos que al reconocer las características de estas transiciones desde una mirada integral de la vida de los sujetos, podemos identificar aquellas amenazas que se presentan muy tempranamente en sus vidas y que provocan procesos de exclusión o inclusiones profundamente desfavorables, al tiempo que permite analizar procesos sociales desde una perspectiva dinámica.

Abordar nuestro objeto de investigación desde la perspectiva del curso de vida, permitió comprender la multiplicidad de factores que intervienen en la construcción de las biografías considerando la variable temporal. Una de las potencialidades de la perspectiva radica en la inclusión de factores explicativos de diferentes niveles - micro y macro- permitiendo evaluar cómo ciertos elementos estructurales se combinan con decisiones individuales para trazar un camino específico en la vida de los sujetos, justamente buscamos dar cuenta de ese interjuego entre capacidades y restricciones/oportunidades. Nos enfocamos en el estudio de las transiciones por entender que pueden tener consecuencias inmediatas o efectos acumulativos en la vida de los individuos, ya sea redireccionando o reforzando las trayectorias de vida, provocando tensiones o afectando importantes dimensiones de la vida cotidiana (Saraví, 2009).

Como resultado del análisis podemos destacar los siguientes puntos sobre los entrevistados:

- Los jóvenes han iniciado desde su temprana infancia, y no exclusivamente desde su juventud un camino de acumulación de desventajas, que terminó ubicándolos en condiciones de extrema vulnerabilidad. Aunque en los últimos años la estructura de oportunidades se ha modificado, provocando inserciones laborales algo más óptimas para padres e hijos, mejoras relativas en los ingresos y accesos a beneficios como la AUH y el PFV, sus efectos son insuficientes porque siguen sin alcanzar para sacarlos de la pobreza.

- Los jóvenes han partido de un lugar común: familias que vivían en condiciones de extrema pobreza, que han necesitado del trabajo infantil para alcanzar su reproducción. De ahí en más las transiciones desde la niñez han pasado por sucesivas situaciones que por distintos motivos los han ubicado en una importante condición de riesgo: inicio de transiciones residenciales y conyugales tempranas, embarazos no deseados, abandono escolar precoz e inserciones laborales precarias basadas en la economía informal y las oportunidades de la zona en la que habitan, son todos factores que hacen a una transición particularmente temprana. 
- La apuesta por la educación formal básica ha aparecido en términos ideales como un camino a recorrer para mejorar potenciales inserciones laborales futuras, pero en los hechos, el tránsito por la escuela ha presentado marcadas deficiencias: el abandono temporario o definitivo, la repitencia y el ausentismo han acompañado a estos sujetos en su trayecto escolar, reforzando su vulnerabilidad.

- Los jóvenes han experimentado transiciones tempranas desde la niñez — si a ésta se la entiende desde el patrón hegemónicohacia la etapa de la juventud y adultez, pero con una particularidad: dichas etapas se presentan entremezcladas, ya que los entrevistados se identifican con lo juvenil, pero a la vez han asumido desde la infancia ciertas responsabilidades propias de la adultez. Si bien comparten las visiones hegemónicas de niñez y juventud, éstas se reapropian según las particularidades de clase, dando como resultado ese mix según el cual se sienten en parte jóvenes y en parte adultos.

Por último, nos interesa plantear dos cuestiones que creemos se deben seguir profundizando en estudios de estas características. Por un lado, el análisis de las particularidades que asume la vivencia de la temporalidad en sectores pobres; por otro, y en relación con ello, la imprevisibilidad y rapidez con que mutan las vidas de los entrevistados. Todos ellos son rasgos que ayudan a pensar y caracterizar las especificidades en la construcción de los cursos de vida y los modos de habitar las temporalidades.

LA Plata (ARGENTINA), DiCIEMBRE 2013

RECIBIDO: DICIEMBRE 2013 ACEPTADO: SEPTIEMBRE 2014 


\section{REFERENCIAS BIBLIOGRÁFICAS}

Bertaux, Daniel (2005): Los relatos de vida. Perspectiva etnosociológica. España: Ediciones Bellaterra.

BLANCO, MERCEDES (2011): «El enfoque del curso de vida, orígenes y desarrollo». Revista Latinoamericana de Población, Año 5, №8.

— y EDITH PACHECO (2003): «Trabajo y familia desde el enfoque del curso de vida: dos subcohortes de mujeres mexicanas». Papeles de población $\mathrm{N}^{\circ} 38$. México: Universidad Autónoma del Estado de México.

Bonifiglio, Juan; Agustín Salvia, Cecilia Tinoboras y Vanina Van RAAP, (2008): «Educación y trabajo. Un estudio sobre las oportunidades de inclusión de los jóvenes tras cuatro años de recuperación económica». En A. Salvia (comp.): Jóvenes promesas. Trabajo, educación y exclusión social de jóvenes pobres en la Argentina, Buenos Aires: Miño y Dávila.

BOURDIEU, PIERRE (2007): El sentido práctico. Buenos Aires: Siglo XXI.

CASTEL, ROBERT (2000): «Las trampas de la exclusión». En: Pobres, pobreza y exclusión social. Buenos Aires: Centro de Estudios e Investigaciones Laborales del CONICET (CEIL).

CORCUFF, PHILIPPE (2013): Las nuevas sociologías. Buenos Aires: Siglo XXI.

DEBERT, GUITA GRIN (1997): «Envelhecimento e curso da vida». Estudos Feministas, Año 5.

ECHARRI CANOVAS, CARlos y JUlieta PÉREZ AMADOR (2007): «El tránsito hacia la adultez: eventos en el curso de vida de los jóvenes en México». Estudios Demográficos y Urbanos $\mathrm{N}^{\circ} 1$.

Elder, Glen H. (1994): «Time, Human Agency, and Social Change: Perspectives on the Life Course». Social Psychology Quarterly $\mathrm{N}^{\circ} 1$.

FeIXA, CARLES (1996): «Antropología de las edades». En J. Prat y A. Martínez (comps.): Ensayos de antropología cultural. Homenaje a Claudio Esteva-Fabregat. Barcelona: Ediciones Ariel.

GIDDENS, ANTHONY (1998): La constitución de la sociedad. Bases para la teoría de la estructuración. Buenos Aires: Amorrortu.

HAREVEN, TAMARA K. (1999): «Novas imagens do envelhecimento e a construção social do curso da vida». Cadernos Pagu $\mathrm{N}^{\circ} 13$.

MACHADO PAIS, JOSÉ (2007): Chollos, chapuzas y changas. Jóvenes, trabajo precario y futuro. Barcelona: Antrhopos.

KATZMAN, RUBÉN y CARLOS FILGUEIRA (1999): «Marco conceptual sobre activos, vulnerabilidad y estructura de oportunidades». Documento de Trabajo de la CEPAL. Montevideo: CEPAL.

KeSSLER, GABRIEL y DENISE MERKLEN (2013): «Una introducción cruzando el Atlántico». En R. CASTEl, G. Kessler, D. MERKLEN y N. Murard (eds.): Individuación, precariedad, inseguridad ¿desinstitucionalización del presente? Buenos Aires: Paidós. 
MUÑIZ TERRA, LETICIA (2012): «Carreras y trayectorias laborales: una revisión crítica de las principales aproximaciones teórico-metodológicas para su abordaje». Revista Latinoamericana de Metodología de las Ciencias Sociales $\mathrm{N}^{\circ} 1$.

SAFA, HELEN (1994): «La mujer en América Latina: el impacto del cambio socioeconómico». En B. Bustos y G. PAlACIO (Comps.): El trabajo femenino en América Latina. Los debates en la década de los noventa. México: Universidad de Guadalajara, Instituto Latinoamericano de Servicios Legales Alternativos.

SARAVÍ, GonZALO (2007): «Nuevas realidades y nuevos enfoques». En G. SARAVÍ (editor): De la pobreza a la exclusión. Continuidades y rupturas de la cuestión social en América Latina. México: CIESAS.

- (2009): Transiciones vulnerables: juventud, desigualdad y exclusión en México. México: CIESAS.

TUIRÁN, RODOLFO (2001): «Estructura familiar y trayectorias de vida en México». En CRISTINA GOMES (compiladora): Procesos sociales, población y familia: alternativas temáticas y empíricas en las investigaciones sobre vida doméstica. México: FLACSO/Miguel Angel Porrúa.

VALles, Miguel (2007): Técnicas cualitativas de investigación social. Madrid: Síntesis.

VARESI, GASTÓN y GERMÁN (2011): «Acumulación, políticas y clases sociales en la Argentina post-convertivilidad». En J. GAMBUNA, B. RAJLAND y D. CAMPIONE (comps.): Hegemonía y proceso de acumulación capitalista en latinoamérica hoy (2001-2007). Buenos Aires: FICYP. 